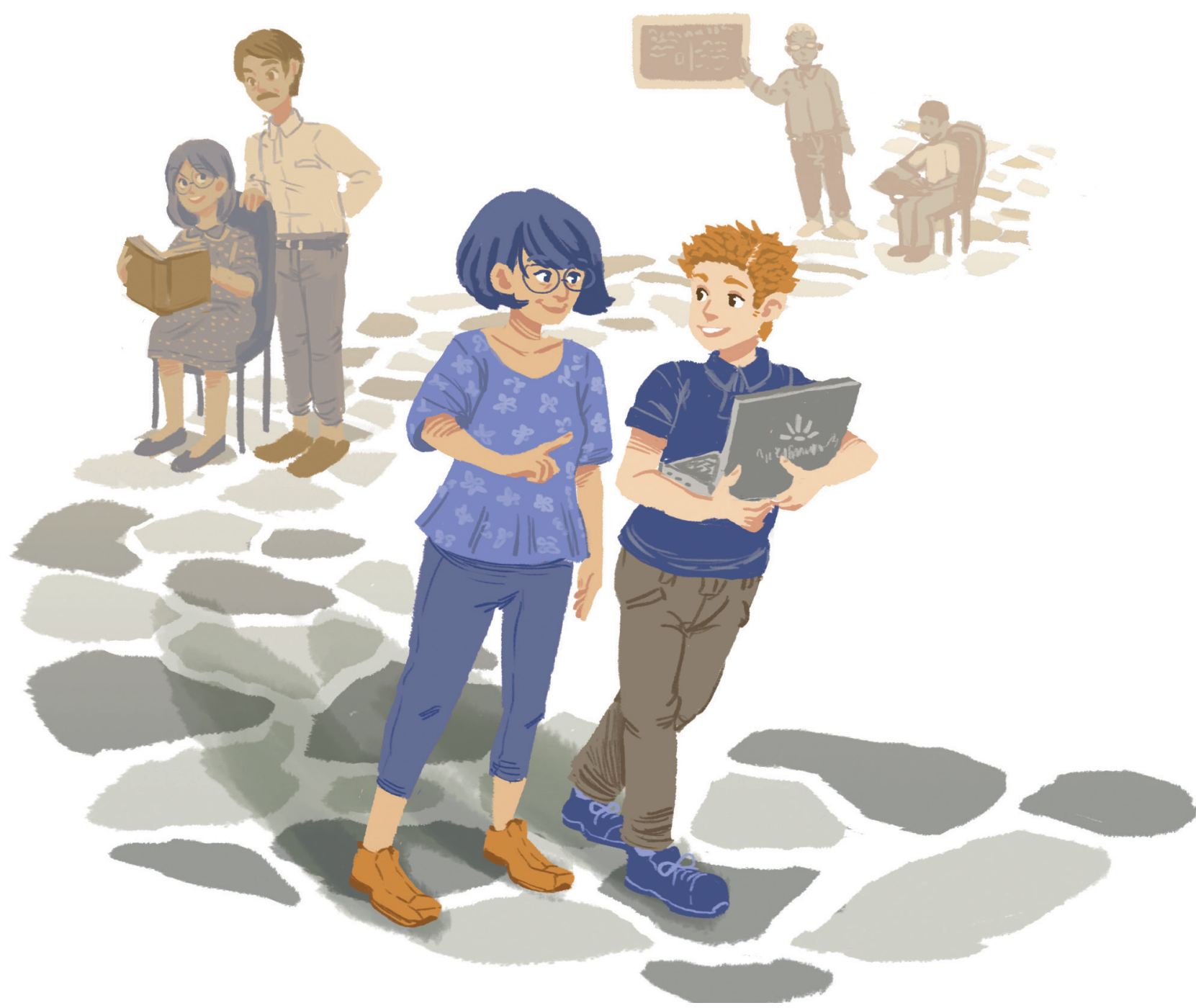

\title{
CAMINHOS DA EXTENSÃO NA UFRN: DESAFIOS E PERSPECTIVAS DO PASSADO E DO PRESENTE
}

Maria de Fátima Freire de Melo Ximenes ${ }^{1}$

Magnólia Fernandes Florêncio de Araújo²

Candida de Souza ${ }^{3}$

Breno Guilherme de Araújo Tinoco Cabral $^{4}$

\section{INTRODUÇÃOO}

Este trabalho tem por objetivo analisar o contexto histórico e social do papel da extensão na formação integral com base nos princípios

da indissociabilidade ensino-pesquisa-extensão, interação dialógica e potencial de transformação por meio da educação.

\footnotetext{
${ }^{1}$ Bióloga pela UFRN e doutora em Ciências Biológicas (Entomologia) pelo Instituto Nacional de Pesquisas da Amazônia. Atualmente é professora associada da UFRN. Tem experiência na área de Parasitologia, com ênfase em Bioecologia de Parasitos e Vetores. Na gestão acadêmica da UFRN atuou como chefe do Departamento de Microbiologia e Parasitologia; Diretora do Centro de Biociências; Vice-Reitora e atualmente é pró-reitora de extensão universitária.

${ }^{2}$ Licenciada e bacharel em Ciências Biológicas pela UFRN. Especialista em Microbiologia (UFRN), Mestre em Bioecologia Aquática (UFRN) e doutora em Ciências (Ecologia de Microrganismos aquáticos) pela UFSCar. Atualmente é professora associado atuando como docente nas disciplinas de Interações Microbianas e parasitárias e Instrumentação para o ensino de Ciências e Biologia para o curso de graduação em Ciências Biológicas.

${ }^{3}$ Doutora pelo Programa de Pós-Graduação em Desenvolvimento Humano e Saúde da UnB e mestre em Psicologia Social pela UFRN. É coordenadora adjunta do Centro de Referência em Direitos Humanos Marcos Dionísio; conselheira do Conselho de Direitos Humanos e Cidadania do RN; membro do Observatório da População Infantojuvenil em Contextos de Violência; e professora da Escola Nacional de Socioeducação.

${ }^{4}$ Graduado em Educação Física pela UFRN, mestre em Ciências da Saúde (UFRN) e doutor em Ciências do desporto pela Universidade de Trás-0s-Montes e Alto Douro. Atualmente é professor da UFRN, pró-reitor adjunto de extensão da UFRN e Membro da comissão de assessoramento de área para áreas avaliadas no ENAD- INEP. Tem experiência na área de Educação Física, com ênfase em ciências do esporte, atuando principalmente nos seguintes temas: maturação, avaliação física e saúde, iniciação esportiva e voleibol.
} 
Trata-se de um estudo qualitativo de natureza crítica e histórico-estrutural a partir de experiências da Universidade Federal do Rio Grande do Norte, de modo a refletir sobre a extensão como potencializadora da formação integral a partir da interação dialógica com a sociedade e da transformação social.
Não há possibilidade de pensarmos o amanhã, mais próximo ou mais remoto, sem que nos achemos em processo permanente de "emersão" do hoje, "molhados" do tempo que vivemos, tocados por seus desafios, instigados por seus problemas, inseguros ante a insensatez que anuncia desastres, tomados de justa raiva em face das injustiças profundas que expressam, em níveis que causam assombro, a capacidade humana de transgressão da ética (FREIRE, 2000, p. 117).

\section{CONTEXTO HISTÓRICO E SOCIAL}

Asideias trazidas pela Reforma Universitária de Córdoba, na Argentina, em 1918, deixaram para a América Latina a extensão como função social da universidade, aliada à interação e diálogo entre a instituição universitária, as pessoas e suas vidas. Surge, portanto, a extensão como resultado de um processo histórico de busca pela democratização da universidade e seu compromisso social.

No Brasil, a extensão universitária é formalizada no Estatuto da Universidade Brasileira (Decreto-Lei no 19.851/1931) e na Lei de Diretrizes e Bases da Educação (Lei $\left.\mathrm{n}^{\circ} 4.024 / 1961\right)$ sob a perspectiva de ensino como transmissão de conhecimento, e da extensão apenas como assistência; ambos dirigidos a atender aos interesses e necessidades da sociedade.

Art. 42. A extensão universitaria será effectivada por meio de cursos e conferencias de caracter educacional ou utilitario, uns e outros organizados pelos diversos institutos da universidade, com prévia autorização do conselho universitario. $\S 1^{\circ}$ Os cursos e conferencias, de que trata este artigo, destinam-se principalmente à diffusão de conhecimentos uteis à vida individual ou collectiva, à solução de problemas sociaes ou à propagacção de idéas e principios que salvaguardem os altos interesses nacionaes.

Art. 46. Alem dos cursos destinados a transmittir o ensino de conhecimento já adquiridos, os institutos universitarios deverão organizar e facilitar os meios para a realização de pesquisas originaes que aproveitem aptidões e inclinações, não só do corpo docente e discente, como de quaesquer outros pesquisadores estranhos à propria universidade (grafia original do Decreto-Lei n ${ }^{\circ}$ 19.851/1931).
Na Lei de Diretrizes e Bases da Educação de 1961 são apresentados, em seu primeiro artigo, os elementos norteadores da missão educacional do País.

Art. $1^{\circ}$ A educação nacional, inspirada nos princípios de liberdade e nos ideais de solidariedade humana, tem por fim:

a compreensão dos direitos e deveres da pessoa humana, do cidadão, do Estado, da família e dos demais grupos que compõem a comunidade;

o respeito à dignidade e às liberdades fundamentais do homem;

o fortalecimento da unidade nacional e da solidariedade internacional;

o desenvolvimento integral da personalidade humana e a sua participação na obra do bem comum;

o preparo do indivíduo e da sociedade para o domínio dos recursos científicos e tecnológicos que lhes permitam utilizar as possibilidades e vencer as dificuldades do meio;

preservação e expansão do patrimônio cultural;

a condenação a qualquer tratamento desigual por motivo de convicção filosófica, política ou religiosa, bem como a quaisquer preconceitos de classe ou de raça.

Com a Reforma Universitária de 1968 (Lei $\mathrm{n}^{\mathrm{o}} 5.540$ ), a Extensão passou a ser obrigatória no ensino superior em um formato de cursos e serviços especiais.

Art. 20. As universidades e os estabelecimentos isolados de ensino superior estenderão à comunidade, sob forma de cursos e serviços especiais, as atividades de ensino e os resultados da pesquisa que lhes são inerentes. 
Nos anos de 1980, com mais liberdade e fortalecimento da sociedade civil, em oposição ao regime autoritário instalado em 1964, o papel da extensão e a relação da universidade com a sociedade foram postos em evidência, particularmente depois da criação do Fórum de Pró-Reitores das Universidades
Públicas em 1987, na Universidade de Brasília. Em 1988, a Constituição Federal, em seu artigo 201, reconheceu a autonomia didático-científica, administrativa e de gestão das universidades, além de ter assegurado o princípio da indissociabilidade entre ensino-pesquisa-extensão.

\section{ANTECEDENTES DA EXTENSÃO UNIVERSITÁRIA NO RIO GRANDE DO NORTE}

Entre as décadas de 1960 e 1970, as ideias de Paulo Freire trouxeram alicerce e disposição aos movimentos voltados à educação popular, especialmente no Nordeste do Brasil, região com elevados índices de analfabetismo. Destacam-se a política de educação e cultura "De pé no chão também se aprende a ler" no Rio Grande do Norte; o Movimento de
Cultura Popular em Recife, Pernambuco e o Movimento de Educação de Base criado pela Confederação Nacional dos Bispos do Brasil (CNBB), que no Rio Grande do Norte se deu por meio do rádio, sobretudo para pessoas residentes em zonas rurais, transmitindo aulas e/ou programas que consistiam no ensino de conteúdos instrucionais diversificados.

\section{DE PÉ NO CHÃO TAMBÉM SE APRENDE A LER}

Em Natal, capital do Rio Grande do Norte, Nordeste do Brasil, a despeito das condições bem mais agravantes que em outras regiões do país, foram dados passos pioneiros e importantes, que, de algum modo, se relacionam à ação extensionista que viria a se configurar com a implantação e fortalecimento da Universidade Federal do Rio Grande do Norte.

Inicialmente uma campanha para erradicação do analfabetismo, transformou-se em uma política de cultura e educação popular para o município de Natal, à época com 140 mil habitantes, na gestão do prefeito Djalma Maranhão e do educador Moacyr de Góes, então secretário de educação de Natal. Impossibilitado de viver em Natal, mudou-se para o Rio de Janeiro e foi um dos criadores da extensão na Universidade Federal do Rio de Janeiro.
Em De Pé no Chão Também se Aprende a Ler crianças, jovens e adultos eram alfabetizados pelos professores da rede municipal de ensino após cursos de capacitação, precedendo as ações auxiliadas por monitores também capacitados com a colaboração da Universidade. O movimento social organizado e a participação da Universidade foram essenciais na transposição de barreiras relacionadas ao espaço físico e à capacitação de pessoas. Acampamentos cobertos com palha de coqueiro eram usados como salas de aula; bibliotecas populares e praças de cultura foram criadas. Em três anos, de 1961 a 1963, a taxa de matrícula e os índices de aprovação foram significativamente elevados. Mas, em 1964, o movimento foi destruído pelo golpe militar sob acusação de "comunização" do Nordeste (USP. Paideia. MOAGYR DE GOES, 1993). 


\section{MÉTODO PAULO FREIRE}

Em dezembro de 1962, um grupo de vinte estudantes da UFRN e três estudantes secundaristas, mobilizados pela União Nacional de Estudantes, participaram do levantamento do universo vocabular da população de Angicos, pequena cidade do Rio Grande do Norte, como etapa inicial do trabalho que se desenvolveria em seguida. Nos primeiros meses de 1963, esses estudantes criaram os Círculos de Cultura e tornaram possível o emprego do Método Paulo Freire fazendo os participantes aprenderem a ler e a escrever em 40 horas, além de despertar o ser político em cada um de seus alunos na ocasião e fazer com que reconhecessem o papel do trabalhador na sociedade. As experiências de vida eram o ponto de partida para a alfabetização. Isso despertou enorme curiosidade, motivo pelo qual o trabalho de Paulo Freire e dos estudantes do Rio Grande do Norte foi amplamente divulgado nos meios de comunicação de vários países. Em Angicos/RN estiveram presentes especialistas em educação e jornalistas de várias partes do mundo, além do presidente da república, João Goulart, no encerramento do curso (GERMANO, 1997).

\section{CRUTAC}

O Centro Rural Universitário de rural efetivando a orientação extensionista da Treinamento e Ação Comunitária - CRUTAC foi criado em agosto de 1966 com o objetivo de interiorizar as ações da Universidade Federal do Rio Grande do Norte por meio de Treinamento e Extensão Universitária, na forma de prestação de serviços à comunidade do interior do estado.

Instalado no município de Santa Cruz, o CRUTAC oportunizou a realização de experiências na atenção social à população

UFRN e a prática multiprofissional no processo de trabalho em saúde.

O CRUTAC, por sua relevância social, foi referência nacional no campo da Extensão Universitária e da Ação Comunitária no âmbito das universidades. Esta experiência foi pioneira em todo o Brasil e difundiu-se nas diversas regiões do país em aproximadamente quarenta instituições públicas de ensino superior.

\section{EXTENSÃO COMO PROCESSO DE FORMAÇÃO INTEGRAL}

A flexibilização curricular de modo a contemplar a extensão e o desafio de uma formação técnico-científica e humanista com base na indissociabilidade ensino-pesquisa-extensão, em diálogo com as demandas sociais, vem sendo objeto de análises e encaminhamentos pelo Fórum de Pró-Reitores de Extensão Universitária ao longo do tempo, buscando e consolidando a extensão como oportunidade de integração social e científica nas universidades brasileiras.

A Lei de Diretrizes e Bases da Educação de 1996 abriu o espaço para propostas pedagógicas mais flexíveis, nas quais se alteram o sentido e as relações entre ensino, pesquisa e extensão, e o reconhecimento do valor do aprendizado por meio de interação com a realidade e vivências com outros saberes:

Art. 43: A educação superior tem por finalidade:

VI - estimular o conhecimento dos problemas do mundo presente, em particular os nacionais e regionais, prestar serviços especializados à comunidade e estabelecer com esta uma relação de reciprocidade; 
VII - promover a extensão, aberta à participação da população, visando à difusão das conquistas e benefícios resultantes da criação cultural e da pesquisa cientifica e tecnológica geradas na instituição.

Cabe, nesse contexto, portanto, o dilema: investigação científica e produção de conhecimento para que e para quem? A despeito dos avanços observados na institucionalização das ações de extensão nas universidades públicas, ainda restam muitos entraves à flexibilização curricular e desenvolvimento de ações de ensino integradas à extensão. Os argumentos usados por diferentes autores, no mínimo, há vinte anos, permanecem atuais e na mesma direção aponta o Plano Nacional de Educação (2014-2024):

(...)uma concepção de currículo, para que seja aceitável precisa extrapolar os limites meramente disciplinares e organizativos inscrevendo-se na tendência crítica que situa o currículo no contexto das relações entre conhecimento e poder, integrando categorias sociais, culturais, políticas e econômicas numa perspectiva culturalista (MOREIRA, 1995, p. 719).

(...) a forte pressão sobreadaptativa que pretende conformar o ensino e a pesquisa às demandas econômicas, técnicas e administrativas do momento, aos últimos métodos, às últimas receitas do mercado, a qual ocasiona a separação/ fragmentação do conhecimento e do próprio homem, relegando, a segundo plano, a cultura humanista e o ensino geral (...). (MORIN, 1999, p. 17).

(...) E, mesmo quando a universidade faz opção por programas ou atividades de extensão, muitas vezes, estas são reduzidas a ações assistencialistas, prestação de serviços ou ligações com o setor produtivo, gerando muito mais uma relação de concessão do que de troca e parceria. Essas se transformaram em ações de aplicação técnica, antes de serem aplicações edificadoras do saber científico, pois se configuraram como prestação de serviço a outrem, a despeito da prestação que traria ao ensino e à própria universidade (...) (TIMOTEO, 2014, p. 22).

\section{REUNI - UFRN}

O Programa de Reestruturação e Expansão das Universidades Federais, lançado em 2007, agregou esforços para a consolidação de uma política nacional de expansão da educação superior pública, conforme previsto no Plano Nacional de Educação - PNE $\left(\right.$ Lei ${ }^{\circ}$ 10.172/2001), que estabeleceu o provimento da oferta da educação superior para pelo menos 30\% dos jovens, na faixa etária de 18 a 24 anos, até 2010. No Rio Grande do Norte, em 2007, apenas 9,8\% dos jovens, entre 18 e 24 anos de idade, estavam matriculados em curso de nível superior, e os egressos da rede pública possuíam bastante dificuldade de acesso, especialmente aqueles que trabalhavam durante o dia e necessitavam estudar à noite.

O Projeto da UFRN apresentou metas no âmbito das seis dimensões do Programa REUNI: ampliação da oferta no ensino superior; reestruturação acadêmico-curricular; renovação pedagógica; mobilidade intra e interinstitucional; compromisso social da instituição e suporte da pós-graduação ao desenvolvimento e aperfeiçoamento qualitativos dos cursos de graduação. No ensino de graduação presencial, por meio do REUNI, houve aumento expressivo da oferta de vagas. Essa expansão só foi possível devido ao aumento da oferta nos cursos existentes e com a criação de 43 cursos novos.

Com a aprovação do Projeto Pedagógico Institucional (PPI 2010-2019), foram previstas ações articuladas visando ao fortalecimento e à disseminação da flexibilidade curricular nos projetos pedagógicos dos cursos de graduação, assumindo o compromisso com uma sólida formação teórica articulada à prática profissional e social, com a interdisciplinaridade e com o diálogo entre os diversos campos dos saberes científicos, cotidianos e da tradição. Essa flexibilização prevê ainda interfaces entre os cursos para possibilitar ao aluno a construção de um percurso formativo ampliado e diversificado, apropriando-se de conhecimentos, habilidades e atitudes que consolidem competências a 
serem construídas no ensino, na pesquisa e na extensão, em busca de uma formação integrada à realidade social.

Portanto, as iniciativas no período de 2008 a 2012 para expandir a participação de docentes, técnicos e discentes nas ações de extensão, bem como dinamizar e qualificar essas ações, tiveram como foco o estímulo à integração da extensão com o ensino e a pesquisa, na perspectiva da indissociabilidade; na promoção do debate e da cooperação entre docentes das diversas unidades, com vistas à formulação e execução de programas integrados; na coordenação de iniciativas para uma inserção qualificada das ações de extensão nos projetos pedagógicos dos diversos cursos, com ênfase nas ações apoiadas pelo PROEXT (MEC), no programa PET, em suas várias versões e no Programa de Extensão Trilhas Potiguares.
Destaca-se, ainda, a realização de eventos como a CIENTEG (Semana de Ciências, Tecnologia e Cultura), seminários em direitos humanos, tecnologias sociais, além do apoio à participação de docentes, técnicos e discentes envolvidos em ações de extensão universitária. As ações resultaram no incremento de projetos, cursos e eventos, e ao correspondente aumento de docentes, técnicos e estudantes envolvidos nas ações. Esta expansão se diversificou e se intensificou pela presença da Universidade em diversos espaços territoriais, urbanos e rurais, do estado do Rio Grande do Norte.

Desta forma, o REUNI -UFRN permitiu ampliar e reafirmar o compromisso social da Universidade por meio de políticas de inclusão, programas de assistência estudantil e extensão universitária (www.reuni.ufrn.br).

\section{UM NOVO MOMENTO DA EXTENSÃO}

Ao longo dos anos, o Fórum Nacional de Pró-reitores de Extensão vem contribuindo com o debate acerca da extensão, como pode ser evidenciado nas reuniões anuais e nas publicações. Conceitos e diretrizes foram estabelecidos na Política Nacional de Extensão (FORPROEX, 2012). A partir disso, observa-se a ampliação do debate em torno da flexibilização e da inserção curricular da extensão nos projetos pedagógicos dos cursos em fóruns regionais e nacionais, posto como mais um desafio a reforçar a importância da extensão universitária na formação profissional, respaldado em artigos e documentos institucionais.

No entanto, o desenvolvimento de processos de extensão crítica e posições ético-político-pedagógicas não dependem unicamente de uma política universitária central, encontra terreno mais propício quando conta com uma política marcada claramente por concepções, prioridades e posicionamentos (TOMMASINO; CANO, 2016).

A reclamação por falta de recursos, de modo particular, com a suspensão do fomento à extensão por meio do PROEXT-MEC, precisa ser suplantada pelo sentido político e formativo da extensão; pela compreensão sobre o quanto nossa maneira de ensinar deve levar em conta as demandas da sociedade e sobre quando a distância entre a teoria que pregamos for igual a nossa prática (DEUS; HENRIQUES, 2017). 
PNE E $O$ DESAFIO DA INSERÇÃO CURRICULAR DA EXTENSÃO NOS PROJETOS PEDAGÓGICOS COM VISTAS À FORMAÇÃO INTEGRAL

O novo Plano Nacional da Educação (LEI $\mathrm{N}^{\circ}$ 13.005, DE 25 DE JUNHO DE 2014), estabelece como estratégias em sua Meta 12:

assegurar, no mínimo, 10\% (dez por cento) do total de créditos curriculares exigidos para a graduação em programas e projetos de extensão universitária, orientando sua ação, prioritariamente, para áreas de grande pertinência social;

fomentar estudos e pesquisas que analisem a necessidade de articulação entre formação, currículo, pesquisa e mundo do trabalho, considerando as necessidades econômicas, sociais e culturais do País;

As atividades de extensão universitária são incentivadoras da aproximação da universidade à comunidade; articuladoras de saberes acadêmicos e sociais; estímulos para a reflexão e para a crítica, indo além do espaço tradicional da sala de aula; e promotoras do deslocamento do espaço de formação para outros locais, favorecendo, assim, o desenvolvimento humano e a transformação social (GARCIA ET AL, 2013, p. 171). Ao atuarem em atividades de extensão, os estudantes se preparam e ganham experiências para melhor conviverem com situações similares futuras, já em suas realidades profissionais, além de passarem a assumir forte compromisso social. Eles podem, no contexto comunitário, rever sua posição pessoal a partir da perspectiva de grupo e podem aprender a construir uma convivência mais humanitária, elevando seus níveis de aceitação das diferenças, uma vez que ampliam a compreensão sobre o seu papel na transformação do mundo.

É nesse contexto que pretendemos discutir a inserção curricular da extensão como estratégia fundamental na formação profissional, o que vem sendo feito pelas universidades brasileiras a partir do que ficou estabelecido nos documentos orientadores da educação. $\mathrm{O}$ princípio da indissociabilidade entre ensino, pesquisa e extensão, estabelecido no artigo 207 da Constituição Federal de 1988, destaca a necessidade de uma formação crítica do estudante na pesquisa e na extensão universitária (BRASIL, 1988), e a flexibilização curricular nos cursos de graduação, concebida na Lei de Diretrizes e Bases da Educação destaca que, para além da formação profissional específica é preciso conceber uma formação cidadã, com consciência na responsabilidade social.

Como um exemplo do que isso significa, podemos pensar que a experiência em atividades de cursos da área da saúde que envolvam não apenas a função curativa ou o tratamento de sequelas, mas também o acompanhamento familiar ganha destaque, pois impõe um novo olhar, uma nova maneira de atuar que envolve pensar não apenas as doenças e suas consequências, mas nas causas sociais que as determinam. Em contextos de extensão, esses aprendizes podem compreender a importância da prevenção para que a saúde se sobreponha à doença, não sendo prioritário atuar sempre sobre a doença.

Ações eventuais já apontam para o efeito que a extensão universitária tem sobre as populações que ela alcança e sobre o próprio profissional em formação. Essas mudanças e seus efeitos requerem uma discussão mais ampliada sobre a necessidade de fazer constar a extensão de maneira obrigatória na formação das diversas profissões e isso poderá garantir uma atuação profissional humanizada, com perspectiva de uma visão mais integral do ser humano, em acordo com a realidade comunitária local. 


\section{CONCLUSÕES}

A despeito dos avanços, o debate e os entraves estão postos. Na prática, ainda se convive com a negação da extensão pelo desconhecimento ou por opção. A expansão e a renovação do quadro docente e técnico, nos últimos quinze anos, traz consigo um quadro de servidores mais capacitado à pesquisa científica e inovação tecnológica, porém sem a compreensão mais ampla do significado da formação integral, sob nossa responsabilidade, em uma instituição pública de ensino superior e do papel e compromisso que se assume ao ingressar na carreira universitária.

Convive-se nos dias atuais com questões antigas e novas, tais como: o reconhecimento de saberes cotidianos e tradicionais destitui o papel central do professor? A extensão como processo de transformação afeta a hegemonia da docência e da investigação científica? $O$ fortalecimento da associação ensino-pesquisa-extensão proporciona espaço para disputas político-acadêmicas nas universidades? Qual a configuração emergente?

O tripé ensino-pesquisa-extensão em que se apoia a Universidade deve contemplar os segmentos menos favorecidos da sociedade e a busca de respostas e soluções para as mazelas decorrentes da exclusão, da violação dos direitos humanos, das ameaças à vida e ao planeta. A política de pós-graduação, mesmo nos cursos com maior inserção social, induz à premiação do produtivismo acadêmico e ensino de pós-graduação em detrimento do ensino de graduação ancorado na missão social das universidades. A busca de alternativas e novos modelos de avaliação se fazem necessários na universidade atual de modo a reverter essa cultura.

Embora compreendendo a extensão como um processo dinâmico e com especificidades que variam de acordo com as áreas, ressalta-se a necessidade de se analisar o quanto e como o conceito de extensão como um processo interdisciplinar, educativo, cultural, científico e político que promove a interação transformadora entre Universidade e outros setores da sociedade vem se desenvolvendo nas universidades.

\footnotetext{
(...) Um dos grandes desafios do nosso século é saber ler bem, um mundo imerso na incerteza. É saber escolher e tratar informações; é transformar informações em conhecimento pertinente, aquele que está inserido num contexto (...) (ALMEIDA; SEVERO; SILVA 2016).
} 


\section{REFERÊNCIAS}

ALMEIDA, M. C.; SEVERO, E.A.; SILVA, F. L. Um sábio na natureza(Orgs). Natal: IFRN Editora, 2015. 178 p.

BRASIL. Constituição da República Federativa do Brasil, 1988

BRASIL. Decreto n. 19.851 de 11 de abril de 1931. Estatuto das Universidades Brasileiras.

BRASIL. Lei n' 4.024 de 20 de dezembro de 1961. Diretrizes e Bases da Educação Nacional.

BRASIL. Lei $n^{\circ}$ 9.394/96, de 20 de dezembro de 1996. Diretrizes e Bases da Educação Nacional.

BRASIL. LEI N 13.005, DE 25 DE JUNHO DE 2014. Plano Nacional de Educação.

BUENO, W. G. Universidade e Responsabilidade Social. Disponível em: http://www. metodista.br/maiscidadania/artigos/universidade-e-responsabilidade-social/. Acesso em 15 jul.2008.

CASTRO, J. O.; TOMMASINO, H. Los caminos de la extensión en América Latina y el Caribe. Santa Rosa: Universidad Nacional de La Pampa, 2017.

DEUS, S.; HENRIQUES, R.L.M. A Universidade Brasileira e sua Inserção social. In: CASTRO, J. O.; TOMMASINO, H. Los caminos de la extensión en América Latina y el Caribe. Santa Rosa: Universidad Nacional de La Pampa, 2017. 230 p.

FORPROEX. Política Nacional de Extensão Universitária. Porto Alegre, 2012 .

FREIRE. P. Pedagogia da Indignação: cartas pedagógicas e outros escritos. São Paulo: Editora UNESP, 2000. 134 p.

GARGIA, B. R. Z.; Bohn, L. R. D.; ARAUJO, M. I. S. UNIVERSIDADE E EXTENSÃO UNIVERSITÁRIA: UMARELAÇÃODIALÓGICAENTREFORMAÇÃOPROFISSIONAL E COMPROMISSO SOCIAL, In: A Extensão universitária como um princípio de aprendizagem / Luiz Síveres (Organizador) — Brasília: Liber Livro, 2013. 272 p

GERMANO, J. W. As quarenta horas de Angicos. Educação \& Sociedade, ano XVIII, n. 59 , agosto/ 1997. 
MOREIRA, A. F. O currículo como política cultural e a formação docente. In:

(Org.). Territórios contestados - o currículo e os novos mapas políticos e culturais. Petrópolis: Vozes, 1995.

MORIN, E. Educação e complexidade: os sete saberes. São Paulo: Cortez, 1999.

Manifiesto Liminar de la Reforma Universitaria. Disponível em: https:/ /es.wikisource. org/wiki/Manifiesto_Liminar_de_la_Reforma_Universitaria. Acesso em 18 de fevereiro de 2018.

SARAIVA, J.L. A Origem e o papel da extensão universitária no Brasil. Brasília Med, v. 44, n. 33, p. 226-234, 2007.

TIMOTEO, R.P.S. A universidade e a flexibilização curricular: dilemas e desafios a enfrentar. Coleção pedadógica. Disponível em: http://www.prograd.ufrn.br/pagina.php?a=col_per_6, acesso em 18 fev. 2018.

TOMMASINO, H.; CANO, A. Avances y retrocesos de la extensión critica en la Universidad de la República de Uruguay, Revista Masquedós, Secretaria de Extensión UNICEN, Tandil, Argentina, n.1, v. 1, pp. 9-23, 2016.

UNIVERSIDADE FEDERAL DO RIO GRANDE DO NORTE. Esta extensão chamada GRUTAC. Natal/RN: UFRN, 1975.

UNIVERSIDADE DE SÃO PAULO. Paidéia. FFGLRP. Ribeirão Preto. 1993 